\title{
Pengelolaan Panen Kelapa Sawit (Elaeis Guineensis Jacq.) di Afdeling 5 Kebun Tinjowan, Sumatera Utara
}

\section{Management Harvesting Oil Palm (Elaeis guineensis Jacq.) In Afdeling 5 Kebun Tinjowan at North Sumatera}

\author{
Hiskia Simanjuntak dan Sudirman Yahya ${ }^{*}$ \\ Departemen Agronomi dan Hortikultura, Fakultas Pertanian, Institut Pertanian Bogor (Bogor Agriculture \\ Unoversity) Jl Meranti, Kampus IPB Dramaga, Bogor 16680, Indonesia \\ Telp. \& Faks.62-251-8629353 e-mail: agronipb@indo.net.id \\ *Penulis untuk korespondensi : syahya@ipb.ac.id \\ Disetujui 14 Mei 2018 / Published online 21 Mei 2018
}

\begin{abstract}
ABSTRACK
The research at Kebun Tinjowan, Simalungun Regency, North Sumatera aims to train the skills and abilities in the field of plantation, as well as gain work experience directly by studying technical and managerial aspects. Observed in harvest management are harvest density, losses, production estimation, quality of harvest work, harvest rotation, harvesting criteria, harvesting needs, harvesting facilities and infrastructure, harvesting organization, and harvest transportation. The results showed that the harvest management needs to be improved. Yield losses prevention needs to be intensified.
\end{abstract}

Keywords: harvest density, losses, harvesting criteria.

\begin{abstract}
ABSTRAK
Penelitian telah dilaksanakan di Kebun Tinjowan, Kabupaten Simalungun, Sumatera Utara bertujuan melatih keterampilan dan kemampuan dalam bidang perkebunan, serta memperoleh pengalaman kerja secara langsung dengan mempelajari aspek teknis maupun manajerial. Hal yang diamati dalam pengelolaan panen adalah angka kerapatan panen, kehilangan hasil, taksasi produksi, kualitas pekerjaan panen, rotasi panen, kriteria panen, kebutuhan tenaga panen, sarana dan prasarana panen, organisasi panen, serta transportasi panen. Hasil pengamatan menunjukkan pengelolaan panen perlu ditingkatkan. Pencegahan kehilangan hasil perlu digalakkan.
\end{abstract}

Kata kunci : angka kerapatan panen, kehilangan hasil, kriteria panen. 


\section{PENDAHULUAN}

Kelapa sawit (Elaeis guineensis Jacq.) adalah salah satu komoditas perkebunan yang sangat unggul. Indonesia menjadi salah satu negara penghasil kelapa sawit terbesar. Direktorat Jenderal Perkebunan mencatat produksi kelapa sawit mengalami peningkatan. Produksi kelapa sawit tahun 2014 mencapai 29.344.480 ton dan tahun 2015 mengalami peningkatan 30.948.931ton (Ditjenbun, 2016).

Tanaman kelapa sawit juga merupakan tanaman penghasil minyak yang telah lama dibudidayakan dan komoditas ekspor non migas yang berperan penting dalam perekonomian Indonesia. Direktorat Jenderal Perkebunan (2016) mencatat volume ekspor minyak kelapa sawit pada tahun 2015 mencapai 13.102.268 ton dengan luas areal perkebunan kelapa sawit Indonesia pada tahun 2015 mencapai 11.444.808 hektar.

Berdasarkan data Direktorat Jenderal Perkebunan, potensi komoditas kelapa sawit perlu dikembangkan lebih lanjut agar produksi dan keuntungan yang diperoleh semakin meningkat. Produksi yang tinggi harus didukung oleh teknik budi daya yang baik. Teknik budi daya yang penting dalam kelapa sawit adalah pengelolaan panen. Panen adalah subsistem produksi di perkebunan kelapa sawit yang menghubungkan kebun dan pabrik kelapa sawit seperti melepaskan buah dari pohon serta mengangkut hasil ke Pabrik (Sunarko, 2014).

Kehilangan hasil pada tahap ini cukup besar. Penyebab kehilangan hasil yaitu tandan matang tidak dipanen, brondolan tertinggal, dan transportasi yang buruk (Siregar, 2014). Pada saat panen terjadi kerusakan buah. Kerusakan pada buah sawit terjadi akibat proses pemanenan yang tidak baik, pengangkutan, dan pembongkaran di loading ramp(Alfiah dan Susanto 2015). Timbulnya masalah kehilangan hasil kelapa sawit dapat diatasi dengan manajemen panen tandan buah segar (TBS) yang tepat. Tujuan umum kegiatan penelitian adalah untuk melatih keterampilan dan kompetensi, serta memperoleh pengalaman kerja dalam bidang agronomi perkebunan secara langsung. Tujuan khusus adalah untuk mempelajari manajemen panen yang tepat di Perkebunan kelapa sawit.

\section{METODE}

Penelitian ini dilaksanakan di Kebun Tinjowan, Sumatera Utara pada bulan Februari 2017 sampai Juni 2017. Kegiatan yang dilakukan sebagai bekerja secara langsung di lapangan sebagai karyawan harian lepas (KHL) selama satu bulan, pendamping mandor selama satu bulan, dan pendamping asisten afdeling selama dua bulan. Kegiatan yang berlangsung setiap hari ditulis dalam jurnal harian. Kegiatan harian yang dilaksanakan selama menjadi KHL yaitu pekerjaan penyisipan, pemeliharaan, serta pemanenan. Pelaksanaan kegiatan tersebut disesuaikan dengan kegiatan kebun pada saat kegiatan penelitian berlangsung.

Kegiatan saat menjadi pendamping mandor adalah mengawasi dan melakukan kerjasama dengan tenaga kerja, membuat jurnal harian, serta membuat taksasi dan rencana kerja. Kegiatan lainnya yaitu melakukan diskusi dengan mandor yaitu tanggung jawab dan hal-hal yang dilakukan ketika melakukan kegiatan di Lapangan. Tugas sebagai pendamping asisten afdeling secara umum yaitu membantu mengawasi semua kegiatan operasional di areal yang akan dikerjakan dapat terlaksana sesuai rencana. Kegiatan khusus yang dilaksanakan selama penelitian difokuskan kepada kegiatan manajemen panen kelapa sawit di Kebun Tinjowan.

Pengamatan dan pengumpulan data dalam kegiatan penelitian meliputi data primer dan data sekunder. Data primer didapatkan dari pengamatan secara langsung pada praktik kerja di lapangan, ataupun dengan wawancara kepada pekerja yang bertugas di lapangan maupun kantor kebun. Data sekunder diperoleh dari perkebunan meliputi lokasi dan letak geografis, organisasi dan manajemen perusahaan, keadaan tanah, iklim 5 tahun terakhir, luas areal dan tata guna lahan, dan produksi Kebun Tinjowan 5 tahun terakhir.

Pengamatan yang dilakukan untuk memperoleh data primer adalah (1) Angka kerapatan panen dan taksasi produksi. Pengamatan dilakukan pada 2 blok. (2) Kehilangan hasil. Pengamatan dilakukan pada brondolan tertinggal dalam satu rotasi panen dengan satu blok per hari kemudian di konversi ke ha berdasarkan ilham (2016) dan di bandingkan dengan standar perusahaan. (3) Rotasi panen. Pengamatan dilakukan dengan wawancara dan pengamatan langsung tiap hari dalam satu minggu pada blok yang diamati.

Kriteria panen. Pengamatan Pengamatan dilakukan dengan wawancara dan mengamati secara langsung terhadap brondolan di piringan dan mutu buah yang dipanen. Mutu buah yang diamati dibandingkan dengan standar mutu perusahaan. (5) Organisasi panen. Pengamatan dilakukan secara langsung dengan mengikuti tahapan koordinasi pelaksanaan panen. (6) Sarana dan prasarana panen. Pengamatan dilakukan pada penggunaan alat panen yang digunakan di Kebun selama kegiatan serta penggunaan APD seperti 
sepatu boot, sarung egrek, dan sarung tangan pada tenaga kerja 2 mandor panen. (7) Kebutuhan tenaga panen. Pengamataan dilakukan secara wawancara dan menghitung jumlah tenaga panen yang tersedia kemudian jumlah tenaga panen dibandingkan dengan standar perhitungan perusahaan. (8) Kualitas pekerjaan panen. Pengamatan dilakukan secara kualitatif pada 5 orang pemanen. Luas diamati yaitu 1 ha pada setiap pemanen. Kriteria diamati yaitu panen tandan buah matang, memotong tangkai tandan buah matang, memotong pelepah. (9) Muat Buah. Pengamatan dilakukan dengan menghitung secara langsung waktu pengangkutan tandan buah matang di TPH ke truck serta menghitung lama waktu pengangkutan dari Afdeling ke PKS. Data primer dan data sekunder yang telah diperoleh dianalisis secara kualitatif dan kuantitatif. Data juga di uji menggunakan uji t-student dan Uji Anova minitab.

\section{Keadaan Iklim dan Tanah}

Curah hujan rata rata Afdeling 5 Kebun Tinjowan pada lima tahun terakhir adalah $1.649,27 \mathrm{~mm}$ per tahun. Kebun Tinjowan memiliki kondisi tanah datar dan bergelombang. Topografi tanah di Kebun Tinjowan memiliki beberapa areal rawa.

Areal Kebun Tinjowan secara geologis tergolong dalam kuarter (Pleistosin) dengan bahan induk tuff liparit toba. Fisiografi kebun ini merupakan daerah lungur vulkan dengan bentuk wilayah datar-berombak, namun terdapat juga areal cekungan (rendahan). Jenis tanah Kebun Tinjowan adalah podsolik merah kekuningan (Typic haludults) dan beberapa podsolik kuning (Typic paleudults). Kesuburan tanah di Kebun Tinjowan berdasarkan hasil analisis tanah 2014 menunjukkan tingkat kemasaman tanah $(\mathrm{pH})$ tergolong agak masam. Kelas kesesuaian lahan
Kebun ini tergolong S2 dan S3. Faktor pembatas terdiri dari faktor pembatas ringan dan sedang. Faktor pembatas ringan yaitu kedalaman efektif dan tekstur tanah. Faktor pembatas sedang yaitu drainasi di areal rendahan terhambat (PTPN IV, 2016).

\section{Luas Areal Konsesi dan Tata Guna Lahan}

Luas areal di Kebun Tinjowan adalah 4.531,32 ha yang terdiri dari 5 afdeling. Luas tanaman menghasilkan 3.571ha dan tanaman belum menghasilkan seluas 456 ha serta penggunaan areal lain 504,32 ha. Pembagian luas areal berdasarkan afdeling dapat dilihat pada tabel dibawah (Tabel 1).

Tabel 1. Luas areal berdasarkan afdeling

\begin{tabular}{ccc}
\hline No & Afdeling & $\begin{array}{l}\text { Luas Areal } \\
\text { (ha) }\end{array}$ \\
\hline 1 & I & $1.058,32$ \\
2 & II & 944 \\
3 & III & 872 \\
4 & IV & 871 \\
5 & V & 786 \\
\hline Total & & $4.531,32$ \\
\hline
\end{tabular}

Sumber : Kantor Tanaman Tinjowan 2016

\section{Keadaan Tanaman dan Produksi}

Tanaman kelapa sawit yang dibudidayakan Kebun Tinjowan PT. Perkebunan Nusantara IV adslah varietas Tenera yang berasal dari persilangan Dura dengan Psifera. Jenis yang digunakan adalah Marihat (PPKS) dan Socfindo. Jarak tanam yang digunakan adalah $9 \mathrm{mx} 9 \mathrm{mx} 9 \mathrm{~m}$ dengan segitiga sama sisi. Populasi tanaman per ha adalah 143 tanaman. Produksi tandan buah segar (TBS) Kebun Tinjowan tidak mengalami peningkatan siginifikan. Hasil produksi 5 tahun terakhir seperti pada (Gambar 1).

\begin{tabular}{ccccc}
89.134 .710 & & & 88.845 .000 & \\
& 80.134 .770 & 78.872 .540 & & \\
\hline \multirow{2}{*}{2012} & 2013 & 2014 & 2015 & 2016 \\
& & Gambar 1. Produksi Kebun Tinjowan 5 tahun terakhir (ton)
\end{tabular}

\section{HASIL DAN PEMBAHASAN}

Pelaksanaan kegiatan penelitian di Adeling 5 Kebun Tinjowan terbagi dua aspek kegiatan yaitu aspek teknis dan aspek manajerial. Aspek teknis adalah kegiatan yang dilakukan sebagai karyawan lapangan. Kegiatan aspek teknis yang dilakukan meliputi pengendalian gulma, pengendalian hama, leaf sampling unit (LSU), aplikasi pupuk hayati, pemupukan, global telling, dan pemanenan. Aspek manajerial adalah kegiatan yang dilakukan mulai pengawasan, evaluasi, perencanaan dan administrasi sebagai mandor dan asisten. Asisten pembimbing memberikan pengarahan pada setiap kegiatan penelitian yang dilakukan. 
Aspek teknis dan aspek manajerial dilakukan dengan bekerja aktif sebagai karyawan harian lepas (KHL), pendamping mandor, dan pendamping asisten. Waktu yang ditetapkan sebagai hari kerja di perusahaan dimulai pukul 06.00-14.00 WIB dan terdapat waktu istirahat selama 30 menit pada pukul 09.30-10.30 WIB. Kegiatan kebun dimulai dengan mengikuti apel pagi. Apel pagi bertujuan untuk memberi pengarahan kerja kepada setiap karyawan dan untuk absensi kehadiran. Apel pagi terdapat dua tahap. Apel pagi tahap pertama berlangsung pada pukul 05.30-05.00 WIB yang dihadiri asisten Afdeling, mandor 1, mandor panen, mandor perawatan, kerani 1 dan kerani produksi. Apel pagi tahap kedua dihadiri oleh seluruh pekerja lapang dipimpin oleh mandor masing masing kegiatan.

\section{Angka Kerapatan Panen dan Taksasi Produksi}

Angka kerapatan panen adalah jumlah pokok yang akan dipanen dalam satu blok tertentu dalam satu hari. Tujuan kegiatan ini adalah untuk mengetahui tenaga pemanen yang dibutuhkan untuk menyelesaikan panen pada luasan tertentu. Taksasi adalah estimasi potensi produksi dengan cara menghitung jumlah TBS yang siap dipanen pada pokok sampel. Jumlah pokok sample yang digunakan pada umumnya yaitu $5 \%$ dari total pokok produktif. Penentuan taksasi produksi dilakukan setelah memperoleh data kerapatan buah matang. Pengamatan angka kerapatan panen (AKP) dan taksasi dilakukan di 2 blok. Hasil pengamatan yang dilakukan seperti pada (Tabel 2).

Tabel 2. Hasil Taksasi produksi dan produksi realisasi

\begin{tabular}{lccccccc}
\hline \multicolumn{3}{c}{ Rencana } & \multicolumn{5}{c}{ Realisasi } \\
\hline $\begin{array}{c}\text { Pokok } \\
\text { sampel }\end{array}$ & Tandan & $\begin{array}{c}\text { AKP } \\
(\%)\end{array}$ & $\begin{array}{c}\text { Produksi } \\
(\text { tandan })\end{array}$ & $\begin{array}{c}\text { Produksi } \\
(\mathrm{kg})\end{array}$ & $\begin{array}{c}\text { Produksi } \\
(\mathrm{kg})\end{array}$ & $\begin{array}{c}\text { Varian } \\
\text { Ton \% }\end{array}$ \\
\hline 05 AL & 189 & 22 & 11,64 & 388 & 6220 & 6800 & 9,32 \\
05AM & 160 & 20 & 12,50 & 340 & 5101 & 5120 & 0,37 \\
\hline
\end{tabular}

Taksasi yang dilakukan di Afdeling 5 Kebun Tinjowan PT.Perkebunan Nusantara IV adalah taksasi harian dengan koordinasi dengan mandor panen satu hari sebelum hari panen. Pengamatan dilakukan pada 2 blok. Hasil yang diperoleh adalah besaran AKP pada selang 11-13 $\%$ dan variasi tonase pada selang 3-7\%. Menurut Akbar (2008) kisaran nilai AKP 25\%-100\% menunjukan produksi yang tinggi, 15-20\% produksi sedang, dan kurang dari $15 \%$ produksi rendah. Nilai variasi tonase pada ke dua blok diamati menunjukan hasil berbeda. Pada Blok 05 $\mathrm{AM}$ hasil variasi tonase menunjukan hasil dalam ambang batas $5 \%$ sedangkan dalam $05 \mathrm{AL}$ variasi tonase yang tinggi. Beberapa faktor yang menyebabkan adalah adanya selisih timbang di PKS karena human eror dan kurang keseragaman tandan per pokok. Turunnya produksi juga dapat menyebabkan angka kerapatan panen rendah atau sebaliknya. Menurut Santoso et al. (2011) perbedaan taksasi dan realisasi yang tinggi atau rendah dapat disebabkan oleh beberapa faktor yaitu kehilangan hasil akibat brondolan tertinggal, tandan buah segar (TBS) tertinggal, dan panen buah mentah. Hal berbeda menurut Miranda (2009) tentang perbedaan ini dapat disebabkan oleh tingkat ketelitian dan jumlah sample. Sample yang tinggi akan lebih menggambarkan fakta dilapangan.

\section{Kebutuhan Tenaga Panen}

Pelaksanaan panen perlu memperhitungkan kebutuhan tenaga panen yang dibutuhkan pada setiap hari pemanenan. Kebutuhan tenaga panen dihitung dengan melihat AKP, Luas panen, berat rata rata tandan, dan populasi rata rata per ha. . Kebutuhan tenaga afdeling 5 dapat dihitung dengan rumus berikut :

$$
\begin{aligned}
\text { Kebutuhan } & \text { tenaga } \begin{array}{c}
\text { panen } \\
\text { Luas afdeling } 5
\end{array} \\
& =\frac{\text { afdeling }}{\text { jumlah kaveld } \times \text { standar luasan panen } / \mathrm{HK}} \\
& =\frac{786 \mathrm{ha}}{5 \times 4 \mathrm{ha} / \mathrm{HK}} \\
& =39 \text { tenaga kerja }
\end{aligned}
$$

Pekerjaan seorang pemanen yaitu menjaga kebersihan panen dan pengutipan brondolan, mutu buah panen, memperhatikan susunan cabang atau pelepah, memotong tangkai tandan buah matang yang dipanen, meletakkan tandan buah matang di TPH, menomori setiap tandan yang diletakkan di TPH, dan melakukan penunasan. Penunasan yaitu melakukan sanitasi tanaman, menghindarkan cabang sengkleh terkena egrek. Hasil menunjukan dengan luasan tanaman menghasilkan (TM) 653 ha afdeling 5 pada pengamatan yang memiliki tenaga kerja tersedia 39 pemanen. Tenaga kerja yang terampil akan lebih memperlancar kegiatan panen. Menurut Wigena et al. (2009) tenaga kerja yang terampil berkorelasi positif terhadap manajemen 
dan produksi. Tenaga kerja yang kurang terampil dapat menghambat proses kegiatan panen dan menyebabkan target panen tidak tercapai. Permasalahan lainnya yang ditemui pada tenaga kerja tersebut adalah ketidakhadiran beberapa pemanen membuat waktu panen akan menjadi lebih

Tabel 3. Kualitas pekerjaan pada pemanen sampel lama pada saat kondisi tandan yang akan dipanen dalam kategori produksi yang tinggi.

\section{Kualitas Pekerjaan Panen}

Pengamatan secara kualitatif dengan mengambil 5 pemanen sampel. Pengamatan dilakukan pada luasan 1 ha per pemanen. Hasil pekerjaan panen sebagai berikut (Tabel 3).

\begin{tabular}{cllllll}
\hline \multirow{2}{*}{ No } & \multicolumn{1}{c}{ Kriteria pengamatan } & \multicolumn{5}{c}{ Pemanen } \\
\cline { 3 - 7 } & Memotong tangkai tandan di piringan & 1 & 2 & 3 & 4 & 5 \\
\hline 1 & Buah mentah tidak dipanen & $\sqrt{ }$ & $\sqrt{ }$ & $\sqrt{ }$ & $\sqrt{ }$ & $\sqrt{ }$ \\
3 & Panen semua TBS matang & $\sqrt{ }$ & $\sqrt{ }$ & $\sqrt{ }$ & $\sqrt{ }$ & $\sqrt{ }$ \\
4 & Pelepah potong 3 & $\sqrt{ }$ & $\sqrt{ }$ & $\sqrt{ }$ & $\sqrt{ }$ & $\sqrt{ }$ \\
5 & TBS di TPH teratur & $\sqrt{ }$ & $\sqrt{ }$ & $\sqrt{ }$ & $\sqrt{ }$ & $\sqrt{ }$ \\
\hline
\end{tabular}

Keterangan $: \sqrt{ }=$ melakukan sesuai kriteria

Kegiatan pemeriksaan kualitas pekerjaan panen perlu dilaksanakan karena berhubungan dengan keterampilan pemanen. Pemanen yang terampil akan melakukan proses kegiatan atau alur panen sesuai prosedur. Tujuan pemeriksaan kualitas pekerjaan panen yaitu untuk menilai hasil dan memperkecil kehilangan produksi (losses). Hasil pengamatan secara kualitatif seperti Tabel 6 menunjukan 5 pemanen sampel yang diamati melakukan kriteria tersebut saat panen di lapangan. Pengamatan dilakukan pada luasan 1 ha per pemanen. Susunan tandan matang di TPH yang baik adalah 5 TBS vertikal. Hal ini bertujuan untuk memudahkan petugas sortasi buah ketika melakukan penghitungan tandan matang yang akan diangkut ke PKS. Beberapa pemanen diluar pemanen sample juga ditemukan kurangnya kebersihan pada piringan atau hanca setiap pemanen. Masalah kebersihan panen yang ditemui diluar pemanen sample di antaranya brondolan teringgal dan terdapat kondisi beberapa tumpukan pelepah digawangan mati tidak diperhatikan.
Pencegahan terhadap kesalahan yang dilakukan pemanen dengan memberikan peringatan dari Mandor maupun Asisten Afdeling.

\section{Kriteria Panen}

Berdasarkan hasil wawancara dan pengamatan langsung dilapangan, kriteria matang panen yang diberlakukan di PT. Perkebunan Nusantara IV adalah 5 brondolan per tandan di piringan. Brondolan yang dimaksu adalah brondolan dalam kondisi normal dan segar. Penggunaan kriteria ini akan lebih memudahkan pemanen dalam mengidentifikasi tandan layak untuk dipanen. Pengamatan kriteria panen dilakukan pada bulan Februari dengan mengamati 100 pokok tanaman yang akan dipanen dan berdasarkan kualitas mutu buah yang dipanen. Mutu buah pada pengamatan ini dibagi menjadi 3 kategori yaitu mentah, matang, dan lewat matang. Hasil pengamatan kriteria panen dan kualitas mutu buah dapat dilihat pada (Tabel 7).

Tabel 4. Hasil Pengamatan mutu buah pada hanca

\begin{tabular}{crrrr}
\hline Ulangan & Tandan buah matang dipanen & Mentah (\%) & Matang (\%) & Lewat matang (\%) \\
\hline 1 & 100 & 0 & 100 & 0 \\
2 & 100 & 0 & 99 & 1 \\
3 & 100 & 0 & 100 & 0 \\
4 & 100 & 0 & 99 & 1 \\
5 & 100 & 0 & 98 & 2 \\
\hline Rata rata & 100 & 0 & 99,2 & 0,8 \\
\hline
\end{tabular}


Hasil pengamatan mutu buah kemudian dianalisis menggunakan uji- $\mathrm{T}$ untuk membandingkan dengan standar perkebunan.

Tabel 5. Hasil uji T-student mutu buah terhadap standar perusahaan

\begin{tabular}{lrrr}
\hline Mutu buah & $\begin{array}{r}\text { Rata- } \\
\text { rata }\end{array}$ & $\begin{array}{r}\text { Standar } \\
\text { perusahaan }\end{array}$ & $\begin{array}{r}\text { p- } \\
\text { value }\end{array}$ \\
\hline $\begin{array}{l}\text { Matang } \\
\text { Lewat }\end{array}$ & 98 & 98 & $0,03 *$ \\
matang & 0,8 & 0 & 0,09 tn \\
\hline
\end{tabular}

Keterangan : tn : tidak nyata pada uji-T taraf 5\%

Rata rata 5 ulangan menunujukan buah mentah 0, matang 98, lewat matang 0.8. Hasil uji t

Tabel 6. Kehilangan hasil saat pemanenan menunjukkan bahwa mutu tandan buah yang dipanen tidak berbeda nyata dengan standar ketentuan. Pengawasan terhadap mutu buah telah dilakukan dengan baik. Menurut Siahaan (2005) dalam menjamin perolehan TBS yang berkualitas, pengawasan yang baik yaitu intensif dan regular.

\section{Kehilangan Hasil}

Kehilangan hasil yang diamati difokuskan pada brondolan tertinggal di piringan. Pengamatan kehilangan hasil ini dilakukan selama 1 rotasi panen. Hasil pengamatan kehilangan hasil seperti pada (Tabel 6).

\begin{tabular}{lcccccc}
\hline $\begin{array}{c}\text { Pengamat } \\
\text {-an }\end{array}$ & $\begin{array}{c}\text { Tanaman } \\
\text { di cek }\end{array}$ & $\begin{array}{c}\text { Buah } \\
\text { tinggal }\end{array}$ & $\begin{array}{c}\text { Tanaman } \\
\text { dipanen }\end{array}$ & $\begin{array}{c}\text { Brondolan tertinggal } \\
\text { di piringan }\end{array}$ & $\begin{array}{c}\text { Brondolan tinggal di } \\
\text { piringan/ha }\end{array}$ & $\begin{array}{c}\text { Buah } \\
\text { tinggal per } \\
\text { ha }\end{array}$ \\
\hline $1(05 \mathrm{AK})$ & 806 & 0 & 110 & 129 & 19,36 & 0 \\
$2(05 \mathrm{AL})$ & 636 & 0 & 108 & 180 & 39,38 & 0 \\
$3(97 \mathrm{Q})$ & 458 & 0 & 89 & 110 & 21,86 & 0 \\
$4(05 \mathrm{AQ})$ & 645 & 0 & 132 & 108 & 22,13 & 0 \\
$5(06$ & 630 & 0 & 112 & 98 & 18,04 & 0 \\
AM) & 635 & 0 & 110 & 125 & 24,15 & 0 \\
\hline Rata rata & 635 & & & \\
\hline
\end{tabular}

Kehilangan hasil adalah hal yang perlu dihindari, karena dapat menyebabkan kerugian terhadap perusahaan. Kehilangan hasil dapat bersumber dari brondolan tertinggal di piringan, tandan matang tidak dipanen, dan kehilangan akibat pencurian. Pengamatan kehilangan ini difokuskan pada brondolan tertinggal di piringan. Hasil pengamatan seperti pada Tabel 9. Hasil tersebut mengambarkan tingkat kebersihan di lapangan. Data tersebut kemudian di uji lanjut untuk melihat kesesuaian dengan standar. Pada Tabel 10 menunjukan nilai uji $\mathrm{T} 0.003$ yaitu belum sesuai dengan ketentuan yang ditetapkan pada kebun Afdeling 5 Tinjowan, namun masih terdapat brondolan teringgal di lapangan. Hal ini juga disebabkan kurangnya kebersihan dan ketelitian pemanen terhadap letak brondolan yang jatuh pada hanca pemanen baik di sekitar dan diluar piringan serta pada tumpukan pelepah di gawangan mati.
Tabel 7. Hasil uji t-student kehilangan hasil brondolan tertinggal di piringan

\begin{tabular}{lccc}
\hline $\begin{array}{l}\text { Kehilangan } \\
\text { hasil }\end{array}$ & $\begin{array}{c}\text { Rata- } \\
\text { rata }\end{array}$ & Standar & p-value \\
\hline $\begin{array}{l}\text { Brondolan } \\
\text { piringan/ha }\end{array}$ & 24,15 & 0 & $0,003 * *$ \\
\hline Keterangan : ** sangat nyata pada uji lanjut taraf 5\%
\end{tabular}

\section{Rotasi Panen}

Rotasi panen adalah jumlah hari panen dalam seminggu atau jarak antara panen pertama di satu blok sampai panen berikutnya di blok yang sama. Rotasi panen yang digunakan pada semester 1 (Januari-Juni) 5/7. Rotasi panen pada semester 1 yaitu dibagi dalam 5 kaveld panen. Rotasi panen semester 2 dilakukan 6/7 yaitu juli hingga desember.

Tabel 8. Perbandingan rotasi panen standar dengan realisasi terhadap pencapaian target produksi afdeling 5

\begin{tabular}{ccccc}
\hline \multirow{2}{*}{ Bulan } & \multicolumn{4}{c}{ Rotasi Panen } \\
\cline { 2 - 5 } & Standar & Realisasi & Target & Produksi \\
\hline Februari & $5 / 7$ & $5 / 7$ & 895.000 & 1.090 .780 \\
Maret & $5 / 7$ & $5 / 7$ & 970.000 & 1.205 .220 \\
April & $5 / 7$ & $5 / 7$ & 1.228 .000 & 1.390 .190 \\
\hline Rata rata & & & 1.031 .000 & 1.228 .730 \\
\hline
\end{tabular}


Pengamatan rotasi panen yang ditetapkan pada semester 1 adalah 5/7 yaitu dalam 7 hari terdapat 5 hari panen dan 2 hari untuk perawatan pabrik. Hal ini juga menjadi dasar penentuan kapveld pada suatu afdeling menjadi 5 kapveld. Rotasi panen berhubungan dengan kualitas TBS. Rotasi panen yang terlambat mengakibatkan banyaknya jumlah brondolan karena banyaknya tandan matang dan lewat matang di areal panen (Nugraha, 2013).

Tabel 11 menunjukan perbandingan antara rotasi panen standar dengan realisasi, serta hubungannya terhadap pencapaian target dari bulan februari hingga april. Realisasi telah sesuai target, hal ini juga dapat disebabkan karena kesesuaian terhadap rotasi panen. Menurut Pahan (2006) bahwa rotasi panen salah satu faktor penting untuk mendapatkan kuantitas dan kualitas yang tinggi.

\section{Organisasi Panen}

Organisasi panen adalah sistem menggambarkan pengerjaan dan koordinasi di kebun. Setiap petugas yang terlibat dalam organisasi panen memiliki tugas dan tanggung jawab agar tujuan panen dapat dilaksanakan dengan baik. Hasil pengamatan secara langsung di Kebun Tinjowan pelaksanaan panen dimulai dengan melakukan apel pagi dipimpin oleh Asisten Afdeling terhadap Mandor. Beberapa pihak yang terlibat dalam organisasi panen mulai dari manager, asisten kepala kebun, asisten afdeling, mandor panen dan P2B, hingga pemanen. Masing masing pihak memiliki peranan atau fungsi. P2B memliki peranan mengontrol mutu buah panen di TPH, mandor panen menghitung kerapatan panen untuk membuat rencana panen esok harinya dan mengawasi kebersihan panen termasuk pengutipan brondolan di piringan. Mandor panen kemudian membuat laporan panen harian dalam PB 24. Mandor 1 dan asisten afdeling melakukan pengawasan keseluruhan dalam proses pemanenan, sedangkan Kepala Dinas Tanaman dan Manajer mengevaluasi pelaksanaan sistem panen.

\section{Kapasitas Panen}

Kapasitas panen dalam pengamatan ini adalah jumlah tandan buah matang yang dapat dipanen oleh pemanen pada satu hari panen dalam ton. Pengamatan kapasitas panen dilakukan dengan wawancara dan melihat langsung serta mengumpulkan data bersama Mandor panen setiap harinya. Data kapasitas panen seperti (Tabel 9).

Tabel 9. Rata-rata hasil panen pemanen bulan Februari

\begin{tabular}{rcc}
\hline No. Pemanen & Rata-rata hasil panen per hari $(\mathrm{kg})$ & Umur Pemanen (tahun) \\
\hline 1 & 2936.3 & 35 \\
4 & 3588.95 & 30 \\
6 & 3740.65 & 35 \\
9 & 2881.15 & 33 \\
11 & 3548.95 & 29 \\
13 & 3511.65 & 28 \\
14 & 3611,00 & 27 \\
15 & 3690.69 & 37 \\
16 & 3752.73 & 28 \\
17 & 3404.52 & 37 \\
\hline
\end{tabular}

Menurut pengamatan yang dilakukan Nugraha (2013) tercapainya kelancaran dalam mencapai kapasitas panen juga dipengaruhi beberapa faktor yaitu jumlah tenaga panen, umur, pendidikan, dan lama kerja. Data yang diperoleh kemudian dikelompokkan berdasarkan umur pemanen untuk di uji melihat pengaruh umur pemanen terhadap capaian kapasitas.

Tabel 10. Pengaruh umur pemanenan terhadap capaian kapasitas

\begin{tabular}{lcl}
\hline Peubah & Rata rata kapasitas panen & p-value \\
\hline Umur pemanen $\leq 30$ & 3574.44 & $0.885^{\text {tn }}$ \\
Umur pemanen $>30$ & 3330.66 & $0.552^{\text {tn }}$ \\
\hline
\end{tabular}

Keterangan $: \mathrm{tn}=$ tidak nyata pada hasil uji anova

Berdasarkan hasil uji anova Tabel 14 teori tersebut tidak sesuai dengan hasil pengamatan di lapangan dan nilai uji anova 0.552 dan 0.885 menunjukkan pengaruh tidak nyata. Beberapa hal 
yang dapat mempengaruhi berdasarkan hasil wawancara dengan Mandor panen lama bekerja dapat mempengaruhi capaian ini.

Muat Buah

Pengamatan dilakukan dengan menghitung secara langsung waktu pengangkutan

Tabel 11. Hasil pengangkutan TBS Afdeling V Kebun Tinjowan

\begin{tabular}{|c|c|c|c|}
\hline Ulangan & Waktu muat (menit) & Waktu ke PKS (menit) & Muatan $(\mathrm{kg})$ \\
\hline 1 & 63 & 41 & 8.3 \\
\hline 2 & 65 & 39 & 8.1 \\
\hline 3 & 63 & 42 & 8.52 \\
\hline Rata-rata & 63,6 & 40,6 & $8.320,7$ \\
\hline
\end{tabular}

Menurut suryono (2012) faktor yang mempengaruhi kelancaran transportasi TBS adalah organisasi potong buah, kondisi jalan, jenis trasnportasi, perawatan transportasi, dan kelancaran pengolahan di Pabrik. Kegiatan transportasi dimulai dari ketika buah sudah dikeluarkan dan diletakkan di TPH. P2B melakukan sotasi buah. Tandan yang telah memenuhi kiteria dan diberi tanda kemudian diangkut ke truck. Proses ini dinamakan muat buah. Kegiatan yang dilakukan di ulang sebanyak 3 kali. Hasil menunjukan seperti Tabel 16 waktu muat memerlukam waktu rata rata 63,6 menit. Tandan matang harus diangkut menuju PKS dengan disertai surat pengantar buah (SPB). Waktu yang dibutuhkan menuju PKS dari afdeling 5 yaiu rata rata 40,6 dengan muatan $8.320 .7 \mathrm{~kg}$.

yang ditemui saat proses muat buah hingga pengangkutan ke PKS yaitu adalah kondisi jalan rusak yang membuat truck terkendala, permasalahan pada alat transportasi atau truck, dan lamanya waktu beberapa pemanen mengeluarkan tandan buah matang dari piringan ke TPH membuat proses muat menjadi lama. Kapasitas yang diangkut truck melebihi kapasitas sebenarnya yaitu $5.000 \mathrm{~kg}$ per truck. Hal ini juga membuat kecepatan jalan truck menuju PKS menjadi lebih lama.

\section{KESIMPULAN}

Kegiatan penelitian yang dilakukan di Afdeling 5 Kebun Tinjowan, PT. Perkebunan Nusantara IV memberikan pengetahuan dan pengalaman dalam melakukan kegiatan teknis maupun manajerial dalam perkebunan kelapa sawit (Elaeis guineensis Jacq). Hasil pengamatan yang dilakukan selama penelitian menunjukkan beberapa aspek pengelolaan panen di Afdeling 5 belum mencapai standar perusahaan seperti tandan buah matang di TPH ke truck serta menghitung lama waktu pengangkutan dari Afdeling hingga ke PKS. Hasil pengamatan kegiatan pengangkutan atau muat buah seperti (Tabel 15). penggunaan APD, kebersihan panen, pengutipan brondolan.

\section{DAFTAR PUSTAKA}

Akbar, A. 2008. Manajemen Panen di Perkebunan Kelapa Sawit (Elaeis guieensi Jacq.) Pantai Bunai Estate, PT. Sajang Heulang, Minamas Plantation, Tanah Bumbu, Kalimantan Selatan [Skripsi]. Institut Pertanian Bogor. Bogor.

Alfiah, C. dan W.H. Susanto. 2015. Penanganan Pasca Panen Kelapa Sawit (Penyemprotan Kalium Sorbat terhadap Mutu Crude Palm Oil). Jurnal Pangan dan Agroindustri 3(1):61-72.

[Ditjenbun] Direktorat Jenderal Perkebunan. 2016. Volume dan Nilai Ekspor Sawit Indonesia. [Internet] [diunduh 2016 November 07] Tersedia pada http//:www.aplikasi.ditjenbun.pertanian.g o.id

Ilham, K. 2016. Manajemen Pemanenan Kelapa Sawit (Elaeis guineensis Jaq.) di Divisi 2 Bangun Kolling Estate PT. Windu Nabatindo Abadi, Bumitama Gunajaya, Agro Group, Kota Waringin Timur, Kalimantan Tengah [Skripsi]. Institut Pertanian Bogor. Bogor.

Miranda, R. 2009. Manajemen Pemanenan Kelapa Sawit (Elaeis guineensis Jacq.) di PT. Gunung Kemasan Estate, Minamas Plantation, Pulau Laut, Kalimantan Selatan. Skripsi. Institut Pertanian Bogor. Bogor.

Nugraha, Y.P. 2013. Manajemen Panen Kelapa Sawit di Kebun Sei Air Hitam. 
Perkebunan Inti Sawit Perkasa 1 Riau [Skripsi]. Institut Pertanian Bogor. Bogor.

Pahan, I. 2006. Panduan Lengkap Kelapa Sawit Manajemen Agribisnis dari Hulu Hingga Hilir. Penebar Swadaya, Jakarta.

PTPN IV. 2016. Rekomendasi Pemupukan Kelapa Sawit Kebun Tinjowan. PT Perkebunan Nusantara IV, Medan.

Santoso, E., H. Sulistyo, dan I. Darmawan. 2011. Peramalan Produksi Kelapa Sawit Menggunakan Peubah Agroekologi di Kalimantan Selatan. Jurnal Agronomi Indonesia. 39(3):193-199.

Siahaan, D. 2005. Penerapan good agriculture practice and good manufacture dalam meningkatkan mutu dan keamanan pangan minyak kelapa sawit. Jurnal Penelitian Kelapa Sawit 13(3):109-118.
Siregar M.I. 2014. Manajemen Pemanenan Kelapa Sawit (Elaeis guineensis Jacq.) di Kebun Tanjung Jati PT. Perkebunan Nusantara II [Skripsi]. Institut Pertanian Bogor. Bogor.

Sunarko. 2014. Budidaya dan pengelolaan Kebun Kelapa Sawit dengan Sistem Kemitraan. Agomedia Pustaka, Jakarta.

Suryono, A. 2012. Pengelolaan Panen Kelapa Sawit di PT. Aneka Intipersada, Kabupaten Siak, Riau [Skripsi]. Institut Pertanian Bogor. Bogor.

Wigena I.G.P., Siregar H., Sudrajat. Dan Sitorus S.R.P. 2009. Desai Model Pengelolaan Kelapa Sawit Plasma Berkelanjutan Berbasis Pendekatan Sistem Dinamis, PT. Perkebunan Nusantara V, Sei Pagar, Kabupaten Kampar, Riau. Jurnal Agroekonomi 27(1):81-108. 